\title{
Growth and development in a lepidopteran with variable instar number, Pseudocoremia suavis (Geometridae), under standard rearing conditions and when parasitised by Meteorus pulchricornis (Hymenoptera: Braconidae)
}

\author{
Emma I. BARRAClOUGH, Elisabeth P.J. BURGESS, Aliesha M. KEAN and Louise A. MALONE
}

The New Zealand Institute for Plant \& Food Research Limited, Mt Albert Research Centre, Private Bag 92169, Auckland Mail Centre, Auckland 1142, New Zealand; e-mails: emma.barraclough@plantandfood.co.nz; elisabeth.burgess@plantandfood.co.nz; louise.malone@plantandfood.co.nz; aliesha.kean@hotmail.com

Key words. Geometridae, Pseudocoremia suavis, Hymenoptera, Braconidae, Meteorus pulchricornis, variable instar number, critical weight ratio, critical weight, developmental polymorphism, instar number, instar duration, gate

\begin{abstract}
Though extra instars are often associated with poor conditions and thought to be a compensation for a low growth rate, the reasons why they are necessary, and for variable instar number existing under standard rearing conditions, are not yet clear. In standard rearing conditions, approximately half of Pseudocoremia suavis larvae had five instars (Type I larvae), and half six instars (Type II larvae). Type II larvae took longer to pupate and reached higher pupal weights than Type I larvae. The extra instar was not related to sexual size dimorphism; Type II larvae were not more likely to be females. Females of both Types pupated later than males and had higher pupal weights; this weight gain was achieved wholly via an extended final instar. Relative growth rates (RGR), instar durations and larval weights on weigh days were otherwise the same for both sexes. For most of the larval period, Type II larvae had lower RGR and lower weights than Type I larvae. They also had shorter $3^{\text {rd }}, 4^{\text {th }}$ and $5^{\text {th }}$ instars than Type I larvae, and the estimated weights at each moult were significantly lower. The Types are discussed in terms of being, in species with weight thresholds for pupation, not optional "strategies" involving different critical weight ratios for larval moults, but as an inevitable consequence of physiological timing constraints upon reaching the critical weights for larval moults causing large variation in size after the moult. Small larvae may then need an extra instar to reach pupation. When parasitised in the second instar by Meteorus pulchricornis, P. suavis larvae produced parasitoids in either their fourth $\left(4^{\text {th }}\right.$ instar emerging (IE)) or fifth instar $\left(5^{\text {th }} \mathrm{IE}\right)$. The estimated moulting weights at each instar of $4^{\text {th }} \mathrm{IE}$ and $5^{\text {th }} \mathrm{IE}$ hosts were very similar to those of Type I and Type II unparasitised larvae respectively, which, together with similarity of instar duration patterns, is strongly suggestive of Types being present within parasitised larvae. The proportion of $5^{\text {th }}$ IE hosts in the much slowergrowing parasitised treatment was greater than the proportion of Type II larvae in the unparasitised treatment, as might be expected if Type II is associated with lower RGR. The lack of further Types appearing is consistent with extra instars being a compensation for small weight after the moult rather than low RGR per se.
\end{abstract}

\section{INTRODUCTION}

Within-species variability in instar number is not uncommon in insects and is widespread over insect taxa, being present in at least 145 species in 12 orders (Esperk et al., 2007a). The reasons for variable instar number are not yet clear. Esperk et al. (2007a) review the phenomenon, and in such species the most common factors associated with a change in instar number are sexual size dimorphism (SSD), inheritance, and environmental factors such as photoperiod, temperature, humidity, and the quality and quantity of food. Where variability in instar number exists, it is also usually found under standard rearing conditions. While gender may predispose a larva to have an extra instar to enable females to achieve a high degree of sexual size dimorphism (Esperk \& Tammaru, 2006; Esperk et al., 2007b), environmental conditions associated with extra instars are usually adverse ones causing lower growth rates and smaller individuals. Manipulating an environmental condition for the worse often causes an increase in the proportion of larvae exhibiting a higher number of instars (Morita \& Tojo, 1985; Casimero et al., 2000; Jensen \& Cameron, 2004; Gould et al., 2005), suggesting that individuals are genetically capable of exhibiting either pheno- type. Therefore it is likely that in most cases having extra instars fits the compensation hypothesis, in which an extra instar enables a slow-growing individual to continue growing for longer and pupate at a normal weight (Esperk et al., 2007a). Nijhout (1975) used starvation experiments to demonstrate that Manduca sexta (L.), which in laboratory populations almost always has five instars (Kingsolver, 2007), has a threshold weight for pupation below which another larval moult will occur instead of pupation. The ability to add instars may allow a minimum pupal size to be reached in varying environmental conditions (Etile \& Despland, 2008) or under varying growth rates associated with a wide host plant range (Casimero et al., 2000).

We examined growth rate, pupal weight and development time of the geometrid Pseudocoremia suavis (Butler), which has been observed to undergo five or six larval instars under standard rearing conditions, to determine whether having six instars was related to SSD, or to having lower growth rates and taking longer to reach the same pupal weight as larvae with five instars. Pseudocoremia suavis is endemic to New Zealand, and variable instar number has been recorded in Canterbury (east coast of the South Island) (Zondag, 1956; Berndt et al., 2004) and now 
in Auckland (northern North Island), while only five instars were mentioned by Dugdale (1958) and Kay (1983) in Rotorua (central North Island). Berndt et al. (2004) referred to those larvae with five instars as Type I and those with six instars as Type II, and this terminology is followed here. Pseudocoremia suavis has overlapping generations with various instars being recorded all year round in Auckland (Burgess et al., 2014), albeit in reduced numbers in winter, and Alma (1975) trapped adults every week of the year in the central North Island. The larvae are highly phototactic in their first instar (Berndt et al., 2004) and may disperse on silk threads (unpubl. observ.), then settle to feed on a wide range of indigenous and introduced evergreen trees (Dugdale, 1958).

We also compared the durations of larval instars of Type I and Type II larvae, and their estimated weights at each moult. Callier \& Nijhout (2011) recently demonstrated in M. sexta that, as well as for the larval-pupal moult (Nijhout 1975), a critical weight operates for larval-larval moults, at which the endocrine cascade leading to moulting is triggered. This critical weight depends on, and is a fixed ratio of, the weight at the beginning of the instar, and limits how big a larva can grow before it must moult. Tracheal surface area is fixed at the beginning of the moult, and the ultimate cause of the moult, as well as the proximate trigger, is very likely to be oxygen levels being limiting towards the late stages of an instar (Greenlee \& Harrison, 2005; Callier \& Nijhout, 2011). Lower critical weights are inducible by hypoxia (Callier \& Nijhout 2011). Therefore, it is not clear why a slower-growing larva would not simply remain in each instar for longer to reach its critical weight, and reach the pupation threshold without needing another instar. Likewise a delay or hiatus in growth ought not to affect the number of instars. This raises the question of whether Type II larvae spend longer in an instar to moult at the same weight, and simply "add" the sixth instar, or whether they moult at lower weights, and if so, why.

Lastly, P. suavis larvae were parasitised in the second instar with Meteorus pulchricornis (Wesmael), a generalist solitary larval endoparasitoid with a very broad host range. P. suavis larvae parasitised by $M$. pulchricornis have previously been observed to continue moulting until M. pulchricornis emerges in later host larval instars (unpubl. observ.), and so how parasitised larvae gain weight over the instars is of interest in terms of whether parasitised larvae appear to have the same physiological constraints. Under parasitism the growth rate was expected to be much reduced, and we investigated whether instar duration and estimated weights at moulting changed under the parasitism-mediated reduction in RGR. Although hosts do not reach pupation, we also compared instar duration, growth rate and estimated moulting weights between hosts producing parasitoids in the $4^{\text {th }}$ or in the $5^{\text {th }}$ instar, to see if these hosts had the characteristics of Type I and II larvae, and, if Types were still present, what proportions these might comprise compared to unparasitised larvae. If extra instars are needed to reach pupation under lower growth rates, a greater proportion of "Type II" might be expected in parasitised larvae, and perhaps even the appearance of further "Types" with more instars before emergence. To our knowledge, "Types" have never been looked for in parasitised larvae. Meteorus pulchricornis is thought to have arrived in New Zealand in the 1990s (Berry, 1997), where it is present as a parthogenetic strain and has been recorded parasitising 35 species in 10 lepidopteran families (Jocelyn Berry, pers. comm.).

\section{MATERIAL AND METHODS}

The experiment consisted of two treatments, unparasitised larvae and parasitised $P$. suavis larvae, reared individually to adulthood or parasitoid emergence under standard rearing conditions. Life history parameters were recorded, including day of moulting, day of parasitoid emergence, day of pupation, day of moth emergence, pupal weights, and twice-weekly larval weights, allowing relative growth rate (RGR), instar durations, final size, total development time and estimated weights at moulting to be compared for the two larval Types, for males and females, and for parasitised larvae producing parasitoids in the $4^{\text {th }}$ or $5^{\text {th }}$ instar. Development time, cocoon weight and number of eggs in the adult were also recorded for parasitoids, as measures of fitness. The experiment was replicated three times over a 7-month period. Unparasitised larvae numbered 141 in total and parasitised larvae 231, the numbers of parasitised larvae being increased after the first replicate because of significant death in parasitised hosts before the time of parasitoid emergence.

\section{Insects}

Pseudocoremia suavis larvae were obtained from a 3-year-old laboratory colony kept at The New Zealand Institute for Plant \& Food Research Limited, Auckland, and fed on surface-sterilised $P$. radiata $\mathrm{D}$. Don foliage. The colony was established from larvae and moths collected at Woodhill Forest, a commercial pine plantation $30 \mathrm{~km}$ north of Auckland, New Zealand (36 $46^{\circ} 37.02^{\prime \prime} \mathrm{S}$, $\left.174^{\circ} 23^{\prime} 19.81^{\prime \prime} \mathrm{E}\right)$, and was initially line-bred to eliminate disease.

A laboratory colony of $M$. pulchricornis was maintained by using Spodoptera litura (F.) (Lepidoptera: Noctuidae) fed on artificial diet (Singh \& Moore, 1985) as hosts. The original colony founders had emerged from Helicoverpa armigera (Hübner) (Lepidoptera: Noctuidae) larvae collected in Hawke's Bay, New Zealand. Meteorus pulchricornis adult females were kept in ventilated 4-L transparent plastic jars with access to honey and 10\% $\mathrm{w}$ : v sugar solution. Females used for parasitising P. suavis in the experiments were $2-4$ weeks old and had been given experience of parasitising a few days before the experiment by being exposed to small $S$. litura larvae for a 2 -h period.

\section{Pseudocoremia suavis diet}

Pseudocoremia suavis larvae were fed an exclusive diet of fresh needles from three isogenic lines of Pinus radiata, two transgenic and one control, to provide enough isogenic food. In a separate analysis, Burgess et al. (2011) demonstrated that neither transgenic pine type had any effect on life history parameters of P. suavis or M. pulchricornis except for a small delay in time to pupation of $P$. suavis between the two transgenic lines, though neither was different from the control, and this effect was considered spurious. However, to ensure any unexpected effects of pine type would be accounted for in the statistical analysis, it was included as a factor in the current analyses and was not found significant. The three transgenes present in both transgenic lines of $P$. radiata were nptII, bla, and $L E A F Y$ genes (see Burgess et al. 2011 for details and transformation methods). The bla gene was regulated by a bacterial promoter that does not lead to expression in $P$. radiata, and there is no likely mechanism for the nptII gene 
or $L E A F Y$ gene in these plants to have any effect on the insects (Burgess et al., 2011).

The plants were 30 cuttings $0.6 \mathrm{~m}$ high and nearly 4 years old, taken from 5 year old transgenic trees grown from embryonic tissue. Cuttings were grown outside in pots for 30 months then transferred to a glasshouse for a further 16 months in natural light conditions at $18-20^{\circ} \mathrm{C}$. Needles were taken from most of the 30 plants at each harvesting. Young, fully expanded needles were taken, between 2 and $10 \mathrm{~cm}$ back from the tips of branches. These were sterilised for $10 \mathrm{~min}$ in $0.1 \%$ sodium hypochlorite solution and rinsed well in water, then dried before use.

\section{Bioassays}

Pseudocoremia suavis neonates were reared for 7 days on pine needles in excess of the number of larvae needed in the experiment, one-third on each pine type. After hatching from the egg, each neonate was transferred to its own ventilated $3.5-\mathrm{mL}$ transparent plastic "autoanalyser" cup (www.sarstedt.com) containing a fascicle of three needles, and kept at $20 \pm 1{ }^{\circ} \mathrm{C}$. The first 7 days were spent in darkness to encourage settling and feeding behaviour, followed by a $16 \mathrm{~L}: 8 \mathrm{D}$ cycle for the remainder of the experiment. After $7 \mathrm{~d}$, larvae had moulted into the second larval instar and all were weighed. Larvae of outlying weight were discarded, and six equal-sized groups of larvae with very similar mean weights and weight ranges were chosen (two from each pine type), and one group of each pine type was randomly assigned to the parasitised treatment and one to the unparasitised treatment. The mean weights of larvae in the unparasitised and parasitised treatments were $1.16 \pm 0.06 \mathrm{mg}$ and $1.16 \pm 0.06 \mathrm{mg}$ for the first replicate, $1.64 \pm 0.06 \mathrm{mg}$ and $1.66 \pm 0.04 \mathrm{mg}$ for the second replicate, and $1.31 \pm 0.07 \mathrm{mg}$ and $1.36 \pm 0.05 \mathrm{mg}$ for the third replicate, none of which pairs, nor the overall means for the unparasitised and parasitised treatments, were significantly different. Reasons for weight differences between replicates are unknown but differences could result from variation in plant quality over the seven months of the trials.

Larvae to be parasitised were exposed to M. pulchricornis the day after weighing, at $8 \mathrm{~d}$ old (Day 8 ). Each larva was gently transferred on a fine paintbrush into a jar with $45 \mathrm{M}$. pulchricornis and then closely observed until a definite parasitisation event was seen. Sometimes this may have been after several unclear attempts by parasitoids, and it is likely that some larvae were superparasitised as in a previous study using this method (Barraclough et al., 2009). The parasitised larva was then immediately removed and put into a new $3.5-\mathrm{mL}$ cup with a fresh set of pine needles. Two jars of 45 parasitoids were used on parasitisation day in each replicate, to parasitise 49 larvae in the first replicate, and 90 in each of two further replicates.

Larvae that died before producing a parasitoid were dissected to check for the chitinised head capsules of first-instar M. pulchricornis larvae, which persist in the host body after the parasitoid moults into its second instar. The parasitising method did not eliminate superparasitism, as approximately $60 \%$ of the preemergence dead larvae were found to contain two or more head capsules, with most having fewer than four. The range of superparasitism in the dead hosts is very similar to that found in all hosts (dead plus successful) in our previous study using the same parasitising method (Barraclough et al., 2009). In that study superparasitism was not found to significantly affect whether a host died before parasitoid emergence, or other life history parameters.

Larvae in the unparasitised treatment were simply transferred by paintbrush to new individual containers with fresh pine on Day 8 .

Larvae were kept supplied with fresh needles and transferred to $40-\mathrm{mL}$ clear plastic containers upon outgrowing the $3.5-\mathrm{mL}$ cups. Larvae were checked daily from Day 9 for survival, moulting, parasitoid emergence, pupation, and moth emergence. Larvae that had already reached the third instar were recorded as moulting on Day 9. Moulting into the second instar occurred in the first 7 days before larvae were assigned to treatments, and was not recorded.

Larvae were individually weighed again when 13 days old, then twice weekly every 3 alternating with 4 days until death, parasitoid emergence, or pupation. An estimate of $P$. suavis neonate mass was obtained by weighing ten groups of ten neonates. Larvae showing signs of preparing to pupate were not weighed, to avoid damaging this vulnerable life stage. Parasitised P. suavis were weighed right up until parasitoid emergence. Pseudocoremia suavis pupae were weighed and were examined to determine gender. If pupae had not yet hardened, they were weighed on the subsequent day.

After parasitoids emerged from their host and formed cocoons, cocoons were placed individually in clean $3.5-\mathrm{mL}$ cups and then weighed 4 days after formation. This delay aimed to reduce variability in the weights that might result if weighing was done during the early period of rapid weight loss which was measured in preliminary investigations. On emergence from their cocoons, the $F_{1}$ adult parasitoids were transferred individually to $75-\mathrm{mL}$ specimen containers with a $1-\mathrm{cm}$ section of cotton wool dental wick soaked in $10 \%$ honey solution, where they were kept for 18 days after hatching and then killed by freezing. The day of killing was chosen to coincide with the middle of the plateau of peak egg load for these synovigenic parasitoids, using the results of Fuester et al. (1993) to estimate this for the temperature conditions of the current experiment. Ovaries of these adults were later dissected out and the number of mature eggs (with pointed ends) were counted. Dissection was performed by using fine forceps to pull on the ovipositor to extract the pair of ovaries from the abdomen onto a microscope slide. The rest of the abdomen was then pulled apart to rinse out loose eggs, and the whole sample examined in a drop of water under a coverslip using a compound microscope at $80 \times$ magnification.

\section{Calculation of estimated weight at moulting, Relative Growth Rate (RGR) and Absolute Growth Rate (AGR)}

The relative growth rate (RGR) $\left(\mathrm{g} \mathrm{g}^{-1}\right.$ day $\left.^{-1}\right)$, was calculated for each larva for the period when its natural log-transformed weights against time formed a generally straight line, usually between 7 and 23 or between 7 and 27 days. Here we call this the "mid-period RGR". For this period the RGR is the calculated as the slope of this line, being $\left(\ln w_{2}-\ln w_{1}\right) /\left(t_{2}-t_{1}\right)$ where $w_{2}$ is weight at time $2, w_{1}$ is weight at time 1 , and $t_{2}-t_{1}$ is the time elapsed (Blackman, 1919). The few larvae that had an unclear straight line period were not used in the RGR analyses.

The estimated weight at each moult for each larva was calculated by interpolating the log-transformed weight on the day of each moult from the straight line part of the graph using the equation above, and then back-transforming.

Overall absolute growth rate (AGR) of an individual was calculated as its final weight (pupal weight or cocoon weight) divided by the development time.

\section{Statistical analyses}

Data were analysed using Minitab 16 (Minitab, 2010) and GenStat (2007). ANOVA (General Linear Model, Minitab) was used to compare parameters between sexes, between instar Types, between unparasitised and parasitised larvae, and between parasitised larvae emerging in the fourth or fifth instar. Natural log data transformations were used where residuals were not normally distributed. Replicate, pine type, instar Type or instar of parasi- 


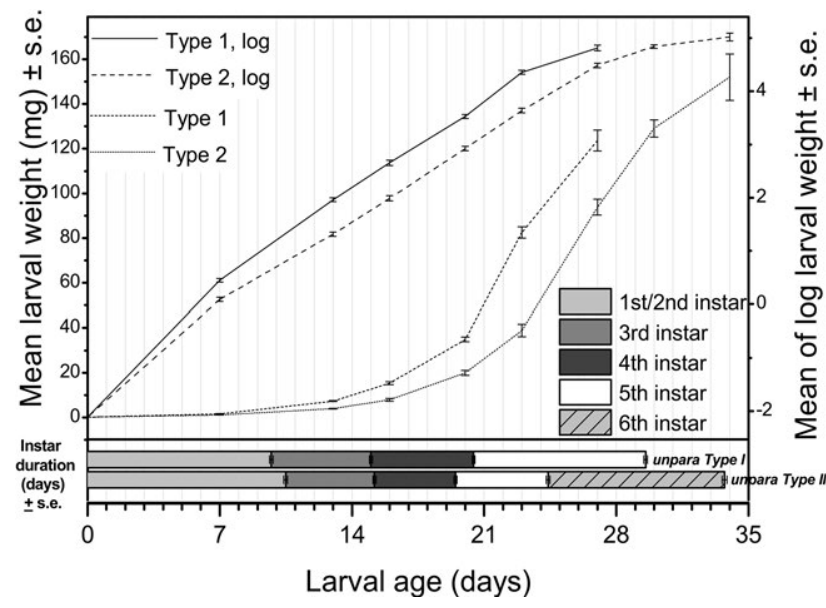

Fig. 1. Unparasitised Pseudocoremia suavis: growth and instar duration of Type I (five instars) and Type II (six instars) larvae. Fitted means are shown, and fitted means of natural log transformed weights. Larvae showing signs of preparing to pupate were not weighed.

toid emergence, and sex (where known) were included as factors in all analyses and adjusted means are reported. Sex was independent of Type - see Results section. Analyses included only the $P$. suavis that pupated in the unparasitised treatment, and only the $P$. suavis successfully producing a parasitoid in the parasitised treatment. General Linear Regression (GenStat) was used to test the association between pupal weight and Day 7 weight, and between development time of the parasitoid and host weight on Day 7. Pearson's Chi-square test, Fisher's exact test, and paired t-test were used to test other associations where specified in the Results section.

\section{RESULTS}

\section{Comparison of unparasitised Pseudocoremia suavis larvae pupating after five instars or after six instars}

Approximately half of the unparasitised larvae pupated at the end of the 5th larval instar $(67,55$ and $39 \%$ in replicates 1, 2 and 3 respectively) and half at the end of the 6th instar $(33,45$, and $61 \%)$, with the replicate effect being significant (Pearson $\chi^{2}=6.625, \mathrm{P}=0.036$, d.f. $=2$ ). Instar Type was significantly associated with instar duration, relative growth rate, larval and pupal weights, and development time. Type II larvae moulted into the third instar $0.8 \mathrm{~d}$ later than Type I (Type I: $\mathrm{N}=68$, mean $=9.7 \pm 0.1$ d; Type II: $\mathrm{N}=55$, mean $=10.5 \pm 0.1 \mathrm{~d} ; \mathrm{P}<0.001, \mathrm{~F}_{1,116}=$ 26.19) but then had a $0.6 \mathrm{~d}$ shorter third instar (Type I: $\mathrm{N}=$

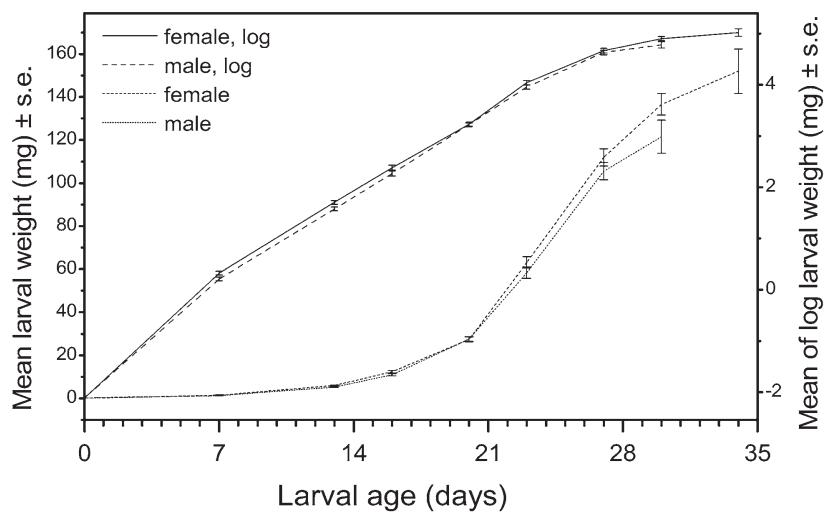

Fig. 2. Unparasitised Pseudocoremia suavis: growth of male and female larvae. Fitted means are shown, and fitted means of natural $\log$ transformed weights. Larvae showing signs of preparing to pupate were not weighed.

68 , mean $=5.3 \pm 0.1 \mathrm{~d}$; Type II: $\mathrm{N}=56$, mean $=4.7 \pm 0.1$ d; $\mathrm{P}<0.001, \mathrm{~F}_{1,117}=24.94$ ) (Fig. 1). Type II larvae moulted into the fourth instar at the same time as Type I larvae but at about half the weight, and then spent $1.1 \mathrm{~d}$ less in the fourth instar (Type I: $\mathrm{N}=66$, mean $=5.4 \pm 0.1 \mathrm{~d}$; Type II: $\mathrm{N}=56$, mean $\left.=4.3 \pm 0.1 \mathrm{~d} ; \mathrm{P}<0.001, \mathrm{~F}_{1,115}=100.94\right)$ (Fig. 1). Type I larvae then spent $9.1 \pm 0.1 \mathrm{~d}(\mathrm{~N}=68)$ in their fifth and final instar, while Type II remained as fifth instar for only $4.9 \pm 0.1 \mathrm{~d}(\mathrm{~N}=56)$ before moulting into a sixth and final instar $9.3 \pm 0.1(\mathrm{~N}=56)$ days in duration. The duration of this final instar, which is extended in both instar types as the larva stops feeding and prepares to pupate, was not significantly different between the two larval types ( $\mathrm{P}$ $\left.=0.305, \mathrm{~F}_{1,117}=1.06\right)$. As the moult into the second instar was not recorded, it is not known whether the later moult into the third instar for Type II larvae is due to a longer first instar, longer second instar, or both. Type II larvae took $4.1 \mathrm{~d}$ longer to develop from hatching to pupation and 4.6 days longer from hatching to adulthood (Table 1). The time spent as pupae was $0.3 \mathrm{~d}$ longer in Type II larvae (Table 1).

Type I larvae gained weight significantly faster than their Type II counterparts (Table 1), with a $10 \%$ greater midperiod RGR. Type II larvae were smaller on the first weigh day at 7 days old, being $71 \%$ the weight of Type I larvae, and $53 \%, 52 \%, 57 \%, 47 \%$ and $76 \%$ on Days $13,16,20$, 23, and 27 respectively, until by Day 30 only Type II larvae remained unpupated (Fig. 1). Type II larvae, however, continued to grow and achieved a greater "last-measured

TABle 1. Developmental parameters of unparasitised Pseudocoremia suavis larvae: comparison between the instar Types. Type I larvae have five larval instars, and Type II larvae have six. RGR is "relative growth rate" (proportion increase in weight per day), AGR is overall "absolute growth rate" (pupal weight per days of development). Means are fitted values from ANOVA tests.

\begin{tabular}{lccc}
\hline Parameter & $\begin{array}{c}\text { Type I } \\
\text { Mean } \pm \text { s.e. }(\mathrm{n})\end{array}$ & $\begin{array}{c}\text { Type II } \\
\text { Mean } \pm \text { s.e. }(\mathrm{n})\end{array}$ & \\
\hline Days to pupate, from neonate & $29.6 \pm 0.2(67)$ & $33.7 \pm 0.2(56)$ & $\mathrm{F}_{1,114}=186.73, \mathrm{P}<0.001$ \\
Days as pupa & $16.7 \pm 0.1(51)$ & $17.0 \pm 0.1(44)$ & $\mathrm{F}_{1,88}=5.73, \mathrm{P}=0.019$ \\
Days to adult, from neonate & $46.2 \pm 0.3(51)$ & $50.8 \pm 0.3(44)$ & $\mathrm{F}_{1,82}=102.63, \mathrm{P}<0.001$ \\
Last-measured larval weight (mg) & $115.6 \pm 2.20(67)$ & $128.1 \pm 2.34(56)$ & $\mathrm{F}_{1,116}=14.62, \mathrm{P}<0.001$ \\
Pupal weight (mg) & $89.03 \pm 1.23(68)$ & $95.33 \pm 1.33(56)$ & $\mathrm{F}_{1,117}=11.52, \mathrm{P}=0.001$ \\
Mid-period RGR $\left(\mathrm{g} \mathrm{g} \mathrm{g}^{-1}\right.$ day $\left.^{-1}\right)$ & $0.246 \pm 0.002(67)$ & $0.224 \pm 0.003(52)$ & $\mathrm{F}_{1,112}=39.64, \mathrm{P}<0.001$ \\
AGR, neonate to pupation $\left(\mathrm{mg} \mathrm{day}^{-1}\right)$ & $3.00 \pm 0.04(68)$ & $2.81 \pm 0.05(58)$ & $\mathrm{F}_{1,119}=7.33, \mathrm{P}=0.008$ \\
\hline
\end{tabular}




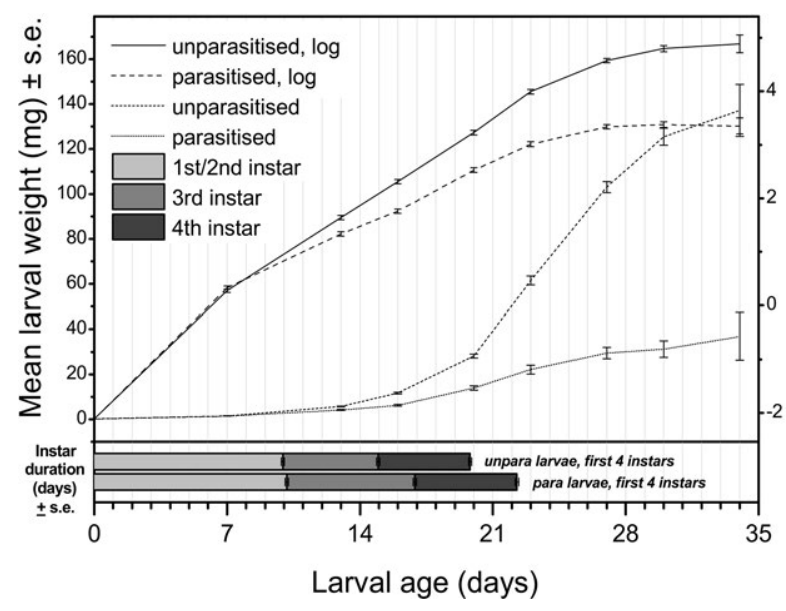

Fig. 3. Comparison of unparasitised and parasitised Pseudocoremia suavis: growth and instar duration of larvae. Fitted means are shown, and fitted means of natural log transformed weights.

larval weight" (weight on the most recent weigh day before pupation) and a $7.1 \%$ greater pupal weight (Table 1) than those that had only five larval instars. Type I larvae, however, achieved the greater overall AGR (pupal weight per total days spent developing), which was $6.4 \%$ greater than that of Type II larvae (Table 1). Estimated weights at each moult were much lower in Type II larvae than in Type I larvae (Table 4).

Over all larvae of both Types, pupal weight was not predicted by larval weight on Day $7\left(\mathrm{P}=0.442, \mathrm{~F}_{1,122}=0.60\right)$, indicating that slower growth may be compensated for by a longer development time.

The proportions of Type I larvae among the replicates did not appear to be related to the mean Day 7 weights of the replicates (see Methods) since the replicates with the highest, mid and lowest proportions of Type I larvae had the lowest, highest and mid mean Day 7 weights respectively. There was no difference in RGR among the replicates.

\section{Effect of sex on unparasitised Pseudocoremia suavis larval development}

Female $P$. suavis larvae took 0.9 days longer to develop from neonate to pupation and produced pupae $10.5 \%$ heavier than did males (Table 2), but females were not more likely to be Type II larvae than Type I larvae (28 females were Type I and 32 females were Type II larvae; 40 males were Type I and 24 males were Type II larvae; $\mathrm{P}=0.104$, Fisher's Exact Test). Fig. 2 shows that this gender differ-

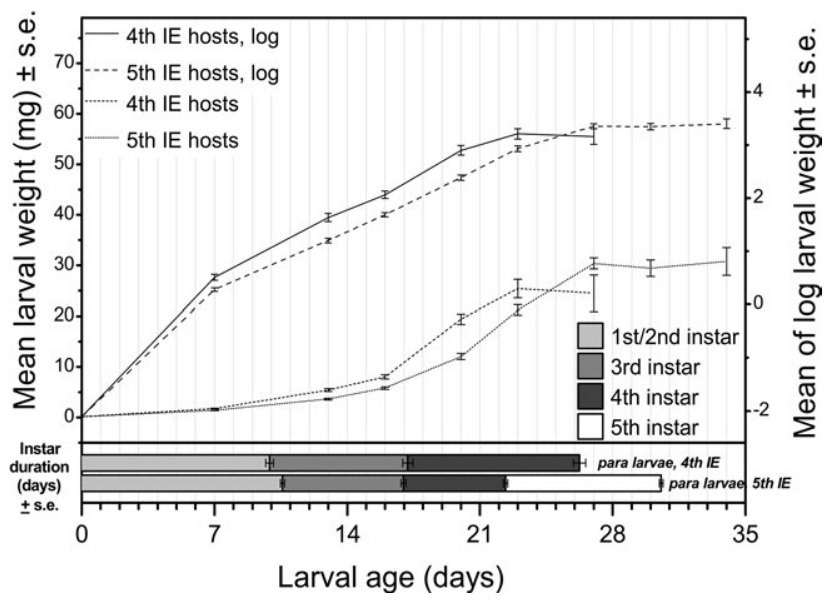

Fig. 4. Parasitised Pseudocoremia suavis: growth and instar duration when parasitoids emerged in the $4^{\text {th }}$ or $5^{\text {th }}$ host instar. Fitted means are shown, and fitted means of natural log transformed weights.

ence in pupal weight comes about in a very different way from the instar Type difference in pupal weight. Male larvae were significantly smaller on Days 7 and 13, respectively $89 \%$ and $87 \%$ of the weight of females (Fig. 2), but there were no significant differences in larval weight on subsequent weigh days. Females did not have a different mid-period RGR to males (Table 2), but by Day 30 only females remained unpupated. Females continued growing for longer in the final instar when growth rate (though not relative growth rate) is highest, to reach a higher lastmeasured larval weight than males before pupating into bigger pupae (Table 2). AGR was $6.8 \%$ higher in females than in males. There were no differences in instar duration between males and females, in both Type I and Type II larvae, until the final instar which was 0.6 days longer for females (female: $\mathrm{N}=60$, mean $=9.5 \pm 0.1 \mathrm{~d}$; male: $\mathrm{N}$ $=64$, mean $\left.=8.9 \pm 0.1 \mathrm{~d} ; \mathrm{P}<0.001, \mathrm{~F}_{1,117}=17.34\right)$. While males pupated earlier, they then spent 2.0 days longer in the pupal form, to emerge as adults not significantly later than females (Table 2).

\section{Effect of parasitism on Pseudocoremia suavis larval development}

Unsurprisingly, parasitism reduced host growth rate (Fig. 3), the mid-period RGR in parasitised larvae being $73 \%$ that of unparasitised larvae (unparasitised: $\mathrm{N}=119$, mean $=0.236 \pm 0.002$; parasitised: $\mathrm{N}=118$, mean $=0.172$ $\left.\pm 0.002 ; \mathrm{P}<0.001, \mathrm{~F}_{1,231}=494.30\right)$, and the mean last-

TABLE 2. Developmental parameters of unparasitised Pseudocoremia suavis larvae: comparison between the sexes. RGR is "relative growth rate" (proportion increase in weight per day), AGR is overall "absolute growth rate" (pupal weight per days of development).

\begin{tabular}{lccc}
\hline Parameter & $\begin{array}{c}\text { Female } \\
\text { Mean } \pm \text { s.e. }(\mathrm{n})\end{array}$ & $\begin{array}{c}\text { Male } \\
\text { Mean } \pm \text { s.e. }(\mathrm{n})\end{array}$ & \\
\hline Days to pupate, from neonate & $32.1 \pm 0.2(59)$ & $31.2 \pm 0.2(62)$ & $\mathrm{F}_{1,114}=10.75, \mathrm{P}=0.001$ \\
Days as pupa & $15.9 \pm 0.1(49)$ & $17.8 \pm 0.1(46)$ & $\mathrm{F}_{1,88}=198.11, \mathrm{P}<0.001$ \\
Days to adult, from neonate & $48.1 \pm 0.3(49)$ & $48.9 \pm 0.3(46)$ & $\mathrm{F}_{1,82}=3.15, \mathrm{P}=0.079$ \\
Last-measured larval weight (mg) & $130.3 \pm 2.23(60)$ & $113.4 \pm 2.22(63)$ & $\mathrm{F}_{1,116}=28.43, \mathrm{P}<0.001$ \\
Pupal weight (mg) & $96.78 \pm 1.26(60)$ & $87.58 \pm 1.25(64)$ & $\mathrm{F}_{1,117}=26.45, \mathrm{P}<0.001$ \\
Mid-period RGR $\left(\mathrm{g} \mathrm{g}^{-1}\right.$ day $\left.^{-1}\right)$ & $0.233 \pm 0.002(58)$ & $0.236 \pm 0.002(61)$ & $\mathrm{F}_{1,112}=1.09, \mathrm{P}=0.298$ \\
AGR, neonate to pupation $\left(\mathrm{mg} \mathrm{day}^{-1}\right)$ & $3.00 \pm 0.05(61)$ & $2.81 \pm 0.04(65)$ & $\mathrm{F}_{1,119}=8.99, \mathrm{P}=0.003$ \\
\hline
\end{tabular}


TABLE 3. Developmental parameters of parasitised Pseudocoremia suavis and their parasitoids: comparison between Meteorus pulchricornis emerging in the $4^{\text {th }}$ and $5^{\text {th }}$ instar. RGR is "relative growth rate" (proportion increase in weight per day), AGR is overall "absolute growth rate" (parasitoid cocoon weight per days of development).

\begin{tabular}{lccc}
\hline Parameters & $4^{\text {th }}$ instar emergence & $5^{\text {th }}$ instar emergence & \\
& Mean \pm s.e. $(\mathrm{n})$ & Mean \pm s.e. $(\mathrm{n})$ & \\
\hline Host mid-period RGR $\left(\mathrm{g} \mathrm{g}^{-1} \mathrm{day}^{-1}\right)$ & $0.181 \pm 0.004(25)$ & $0.168 \pm 0.003(93)$ & $\mathrm{F}_{1,112}=7.12, \mathrm{P}=0.009$ \\
Host weight on Day $7(\mathrm{mg})$ & $1.74 \pm 0.08(27)$ & $1.38 \pm 0.05(103)$ & $\mathrm{F}_{1,124}=14.75, \mathrm{P}<0.001$ \\
Last-measured larval weight of host $(\mathrm{mg})$ & $26.08 \pm 1.17(27)$ & $34.65 \pm 0.68(101)$ & $\mathrm{F}_{1,122}=39.93, \mathrm{P}<0.001$ \\
Days to parasitoid emergence & $18.2 \pm 0.4(27)$ & $22.5 \pm 0.3(103)$ & $\mathrm{F}_{1,124}=75.4, \mathrm{P}<0.001$ \\
Cocoon weight $(\mathrm{mg})$ & $5.69 \pm 0.23(24)$ & $7.03 \pm 0.13(101)$ & $\mathrm{F}_{1,119}=25.32, \mathrm{P}<0.001$ \\
AGR of parasitoids $\left(\mathrm{mg} \mathrm{day}^{-1}\right)$, & $0.30 \pm 0.01(26)$ & $0.32 \pm 0.01(101)$ & $\mathrm{F}_{1,121}=0.66, \mathrm{P}=0.419$ \\
oviposition to cocoon formation & $37.1 \pm 1.6(23)$ & $40.3 \pm 0.9(94)$ & $\mathrm{F}_{1,111}=2.94, \mathrm{P}=0.089$ \\
Number of eggs in adult parasitoid's ovaries & $10.0 \pm 0.1(24)$ & $10.0 \pm 0.1(95)$ & $\mathrm{F}_{1,113}=0.07, \mathrm{P}=0.786$ \\
\hline Days in cocoon & & &
\end{tabular}

measured larval weight of parasitised larvae was $26 \%$ of that of unparasitised larvae (unparasitised: $\mathrm{N}=124$, mean $=119.64 \pm 1.46 \mathrm{mg}$; parasitised: $\mathrm{N}=128$, mean $=31.35$ $\left.\pm 1.49 \mathrm{mg} ; \mathrm{P}<0.001, \mathrm{~F}_{1,246}=1761.23\right)$. The difference in weight between parasitised and unparasitised larvae was significant by the time larvae were weighed $5 \mathrm{~d}$ after parasitisation (unparasitised: $\mathrm{N}=126$, mean $=5.69 \mathrm{mg}$, s.e. $=$ 0.18 ; parasitised: $\mathrm{N}=130$, mean $=4.18 \mathrm{mg}$, s.e. $=0.18$, $\left.\mathrm{F}_{1,250}=35.22, \mathrm{P}<0.001\right)$ and the difference increased at each subsequent weighing occasion, remaining significant throughout the larval period (Fig. 3).

Following parasitisation in the second instar, P. suavis larvae moulted into the third instar with no significant delay compared with unparasitised larvae (Fig. 3). However, on parasitisation day individual larvae would have been in the second instar for differing lengths of time, potentially masking any effect of parasitism on developmental rate within the remaining portion of the second instar. Also, as larvae were parasitised on average only 2 days before the end of the second instar, daily observations are unlikely to have been sufficiently frequent to detect any small delay in moulting by parasitised individuals. Duration of the third instar was significantly longer by $1.8 \mathrm{~d}$ in the parasitised treatment than in the unparasitised treatment (unparasitised: $\mathrm{N}=124$, mean $=5.0 \pm 0.1 \mathrm{~d}$; parasitised: $\mathrm{N}=$ 129 , mean $\left.=6.8 \pm 0.1 \mathrm{~d}, \mathrm{~F}_{1,247}=173.31, \mathrm{P}<0.001\right)$, and the fourth instar of parasitised hosts that completed the fourth instar was significantly greater by $0.6 \mathrm{~d}$ (unparasitised: $\mathrm{N}=$ 123 , mean $=4.8 \pm 0.1 \mathrm{~d}$; parasitised: $\mathrm{N}=103$, mean $=5.4$ $\pm 0.1 \mathrm{~d}, \mathrm{~F}_{1,220}=16.37, \mathrm{P}<0.001$ ) (Fig. 3).

Over all parasitised hosts, the development time of the parasitoid was inversely associated with host weight on parasitisation day, i.e. larger hosts produced parasitoids sooner $\left(\mathrm{P}<0.001, \mathrm{~F}_{1,128}=45.44\right.$, adjusted $\left.\mathrm{r}^{2}=25.6 \%\right)$.

\section{Comparison of $4^{\text {th }}$ instar-emerging parasitoids (and their hosts) with $5^{\text {th }}$ instar-emerging parasitoids (and their hosts)}

Most parasitoids ( $79.2 \%$, i.e. 103 of 130$)$ emerged from fifth instar hosts, while the remainder emerged from fourth instar hosts. This was subject to the replicate; $40.9 \%(\mathrm{~N}=$ 22), $10.5 \%(\mathrm{~N}=57)$, and $23.5 \%(\mathrm{~N}=51)$ of the larvae in the first, second and third replicates respectively emerged in the fourth instar (Pearson $\chi^{2}=9.293, \mathrm{P}=0.010$, d.f.
=2). Hosts giving rise to M. pulchricornis in the fourth instar ( $4^{\text {th }}$ IE hosts) had been of greater initial weight on parasitisation day than those giving rise to parasitoids in the fifth instar ( $5^{\text {th }}$ IE hosts) (Table 3 and Fig. 4). $5^{\text {th }}$ IE hosts took $0.7 \mathrm{~d}$ longer to moult into third instar than $4^{\text {th }} \mathrm{IE}$ hosts ( $4^{\text {th }} I E: N=27$, mean $=9.9 \pm 0.2 d ; 5^{\text {th }} I E: N=103$, mean $\left.=10.6 \pm 0.1 \mathrm{~d}, \mathrm{~F}_{1,124}=9.11, \mathrm{P}=0.003\right)$ but then spent $0.9 \mathrm{~d}$ less in the third instar $\left(4^{\text {th }} \mathrm{IE}: \mathrm{N}=27\right.$, mean $=7.3 \pm$ $0.3 \mathrm{~d}$; 5th IE: $\mathrm{N}=102$, mean $=6.4 \pm 0.1 \mathrm{~d}, \mathrm{~F}_{1,123}=10.74$, $\mathrm{P}=0.001$ ) (Fig. 4). The fourth instar of $4^{\text {th }} \mathrm{IE}$ hosts (the emergence instar) was much longer than the fourth instar of $5^{\text {th }} \mathrm{IE}$ hosts $\left(4^{\text {th }} \mathrm{IE}: \mathrm{N}=27\right.$, mean $=9.1 \pm 0.3 \mathrm{~d}$; 5 th $\mathrm{IE}$ : $\mathrm{N}=103$, mean $\left.=5.4 \pm 0.1 \mathrm{~d}, \mathrm{~F}_{1,124}=170.05, \mathrm{P}<0.001\right)$, and both $4^{\text {th }}$ IE and $5^{\text {th }}$ IE hosts had an incomplete final emergence instar that was extended compared with their previous instars (Fig. 4). The extended final emergence instar was $0.9 \mathrm{~d}$ longer in $4^{\text {th }} \mathrm{IE}$ hosts than $5^{\text {th }} \mathrm{IE}$ hosts $\left(4^{\text {th }}\right.$ IE: $\mathrm{N}=27$, mean $=9.0 \pm 0.2 \mathrm{~d}$; 5 th IE: $\mathrm{N}=102$, mean $=$ $8.1 \pm 0.1 \mathrm{~d}, \mathrm{~F}_{1,123}=17.56, \mathrm{P}<0.001$ ) (Fig. 4). $5^{\text {th }}$ IE hosts had a lower mid-period RGR than that of $4^{\text {th }}$ IE hosts (Table 3 ), and weights were significantly lower on all weigh days between day 7 and 20 (Fig. 4). Estimated weights at each moult were much lower in $5^{\text {th }} \mathrm{IE}$ hosts than in $4^{\text {th }} \mathrm{IE}$ hosts (Table 4). $5^{\text {th }}$ IE parasitoids emerged $4.3 \mathrm{~d}$ (24\%) later from 33\% larger hosts, and formed 24\% larger cocoons (Table 3). It can be seen in Fig. 4 that at the time of $4^{\text {th }}$ IE hosts reaching peak weight on Day 23 before levelling off in weight prior to parasitoid emergence, $5^{\text {th }} \mathrm{IE}$ hosts were only $83 \%$ the weight of $4^{\text {th }}$ IE hosts. AGR (cocoon weight divided by days from parasitisation to emergence) was no different between $4^{\text {th }}$ IE and $5^{\text {th }}$ IE parasitoids (Table 3 ). Despite the cocoon size difference, cocoons from both host instars took 10 days to develop into adults whose ovaries did not contain significantly different numbers of eggs (Table 3). Because P. suavis were sexed in the pupal stage, we did not know the sex of the larval hosts or how this affected parasitoid growth. However, as the growth curve and instar durations were the same between sexes except for the final instar, host sex is unlikely to have affected parasitoids.

\section{Comparison of $4^{\text {th }}$ and $5^{\text {th }}$ IE parasitised larvae with Type I and II unparasitised larvae, respectively}

The estimated weights at which $4^{\text {th }}$ IE hosts moulted into their third and fourth instars corresponded closely to, 
TABLE 4. Means of estimated weights of Pseudocoremia suavis larvae at the beginning of each instar. Of unparasitised larvae, Type I larvae have five larval instars, and Type II have six. Of parasitised larvae, larvae from which parasitoids emerged in the fourth or fifth host instar are denoted $4^{\text {th }} \mathrm{IE}$ and $5^{\text {th }} \mathrm{IE}$ respectively. Means within an instar that do not share a letter are significantly different (using Bonferroni correction for multiple comparisons with $\mathrm{P} \leq 0.001$, following ANOVA).

\begin{tabular}{|c|c|c|c|c|c|c|}
\hline \multirow{3}{*}{ Instar } & \multicolumn{4}{|c|}{ Mean estimated weights \pm s.e. $(\mathrm{mg})$ of larvae at the start of each instar (n) } & & \\
\hline & \multicolumn{2}{|c|}{ Unparasitised larvae } & \multicolumn{2}{|c|}{ Parasitised larvae } & & \\
\hline & Type I & Type II & $4^{\text {th }} \mathrm{IE}$ & $5^{\text {th }} \mathrm{IE}$ & & \\
\hline third & $3.09 \pm 0.06(67) \mathrm{A}$ & $2.44 \pm 0.07(52) \mathrm{B}$ & $2.96 \pm 0.10(24) \mathrm{A}$ & $2.42 \pm 0.05(93) \mathrm{B}$ & $\mathrm{F}_{3,228}=28.71$ & $\mathrm{P}<0.001$ \\
\hline fourth & $11.31 \pm 0.21(67) \mathrm{A}$ & $6.84 \pm 0.23(52) \mathrm{B}$ & $10.79 \pm 0.33(25) \mathrm{A}$ & $7.19 \pm 0.18(93) \mathrm{B}$ & $\mathrm{F}_{3,229}=108.17$ & $\mathrm{P}<0.001$ \\
\hline fifth & $43.06 \pm 0.66(67) \mathrm{A}$ & $17.96 \pm 0.73(52) \mathrm{B}$ & & $17.66 \pm 0.57(93) \mathrm{B}$ & $\mathrm{F}_{2,205}=476.56$ & $\mathrm{P}<0.001$ \\
\hline sixth & & $53.72 \pm 1.15(52)$ & & & & \\
\hline
\end{tabular}

and were not significantly different from, the estimated weights at which Type I larvae moulted into their third and fourth instars (Table 4). Similarly, the weights at which $5^{\text {th }}$ IE hosts were estimated to have moulted into their third, fourth and fifth instars were close to and not significantly different from the estimated weights at which Type II larvae moulted into their third, fourth and fifth instars (Table 4). The proportion of parasitised hosts that were $5^{\text {th }}$ IE was higher than the proportion of unparasitised $P$. suavis that were Type II larvae in all three replicates $(59,90$, and $77 \%$ compared with 33,45 , and $61 \%$ ), and the parasitised mean was significantly higher (unparasitised: $\mathrm{N}=3$, mean $=$ $46.32 \pm 8.25 \%$; parasitised: $\mathrm{N}=3$, mean $=75.01 \pm 8.80 \%$, paired $\mathrm{t}=3.41, \mathrm{P}=0.038$ ).

Estimated weights at moulting for all parasitised larvae together were lower than for all unparasitised larvae together, when moulting into the third (unparasitised: $\mathrm{N}=$ 119 , mean $=2.80 \pm 0.05 \mathrm{mg}$; parasitised: $\mathrm{N}=118$, mean $=2.5 \pm 0.5 \mathrm{mg}, \mathrm{F}_{1,231}=12.50, \mathrm{P}<0.001$ ), fourth (unparasitised: $\mathrm{N}=119$, mean $=9.32 \pm 0.23 \mathrm{mg} ;$ 5th IE: $\mathrm{N}=118$, mean $\left.=8.10 \pm 0.24 \mathrm{mg}, \mathrm{F}_{1,231}=13.72, \mathrm{P}<0.001\right)$ and fifth instar (unparasitised: $\mathrm{N}=119$, mean $=31.84 \pm 0.97 \mathrm{mg}$; parasitised: $\mathrm{N}=93$, mean $=18.39 \pm 1.15 \mathrm{mg}, \mathrm{F}_{1,206}=78.49$, $\mathrm{P}<0.001)$. However, if $4^{\text {th }} \mathrm{IE}$ and $5^{\text {th }} \mathrm{IE}$ are considered to be Type I and II, and Type is included as a factor, this difference disappears for moults into the third (unparasitised: $\mathrm{N}=119$, mean $=2.77 \pm 0.05 \mathrm{mg}$; parasitised: $\mathrm{N}=118$, mean $=2.69 \pm 0.05 \mathrm{~d}, \mathrm{~F}_{1,230}=1.44, \mathrm{P}=0.231$ ), fourth (unparasitised: $\mathrm{N}=119$, mean $=9.10 \pm 0.15 \mathrm{mg}$; parasitised: $\mathrm{N}$ $=118$, mean $\left.=9.14 \pm 0.17 \mathrm{mg}, \mathrm{F}_{1,230}=0.04, \mathrm{P}=0.847\right)$ and fifth instar (unparasitised: $\mathrm{N}=119$, mean $=30.51 \pm 0.48$ $\mathrm{mg}$; parasitised: $\mathrm{N}=93$, mean $=30.21 \pm 0.74 \mathrm{mg}, \mathrm{F}_{1,205}=$ $0.11, \mathrm{P}=0.743$ ). Thus the apparent difference between unparasitised and parasitised estimated moult weights, which is especially marked in the moult into the $5^{\text {th }}$ instar when there were no "Type I" parasitised larvae left, can be attributed to the greater percentage of "Type II" in the parasitised treatment.

\section{DISCUSSION}

Unparasitised $P$. suavis in our study underwent either five ("Type I", $54 \pm 8 \%$ ) or six larval instars ("Type II", $46 \pm 8 \%$ ). Type II larvae had a longer mean development time and higher mean pupal weight, but this was not related to sexual size dimorphism; the proportion of Types was not different between the sexes. Females had a larval period 3\% longer and pupae 11\% heavier than males, but within Types this size difference was achieved by females simply spending a day longer in the final instar, the growth curve and instar durations otherwise being the same. Pupal or adult mass in female insects is generally strongly correlated with fertility (Honek, 1993) and females of other lepidopteran species with more extreme SSD (sometimes a doubling in pupal size) may develop through additional instars (Esperk \& Tammaru, 2006; Esperk et al., 2007b), but that was not the case here.

In contrast to the sex difference, Type II P. suavis larvae had lower mean weights and lower mean RGR than Type I larvae for most of their developmental period (until Type I larvae approached pupation). This supports the hypothesis that extra instars compensate for low growth rates to reach a pupation threshold. Type II larvae then went on to achieve a 7\% higher pupal weight than Type I larvae by developing for $14 \%$ longer, their growth being spread over six instars. This raises the possibility that six instars could be a life-history "strategy", if larger pupae are "worth" the longer developmental time in some environmental conditions. Interestingly, in our Type II larvae, instars 3 and 4 were shorter by 0.6 and $1.1 \mathrm{~d}$ than in Type I larvae, with moults occurring at much lower estimated weights, whereas we might expect longer instars from slower-growing larvae as they take longer to reach their critical weight for moulting (see Introduction). Costs of moulting include loss of feeding time (Esperk \& Tammaru, 2004), loss of biomass in the exuvia, greater vulnerability to predators during the moult (Sehnal, 1985), and increased chance of fatal mishaps such as inability to discard the old head capsule or epidermis as we have sometimes observed in P. suavis. Given these costs, we might expect it to be beneficial for larvae to reduce the number of total instars (Etile \& Despland, 2008), and remain in each instar for as long as they are not being metabolically limited. However, our Type II larvae moulted at instar: instar weight ratios (the ratio of the weight at the beginning of an instar to the weight at the beginning of the previous instar) well below those seen to be possible in Type I larvae. Lepidopteran larvae can moult below their critical weights during restricted feeding, sometimes undergoing "stationary moults" (Safranek \& Williams, 1984; Esperk et al., 2007a), possibly triggered by the slow build-up of ecdysone secreted at a basal level 
by the prothoracic glands (Callier \& Nijhout, 2011). Thus it seems that even very small larvae cannot remain in the same instar indefinitely and that other, time-dependent constraints may exist, and in larvae with very low RGR these constraints may trigger moulting before size-dependent constraints do. However, we would expect such moults to occur after a longer time than Type I instar durations, not shorter as observed for Type II $P$. suavis larvae, suggesting that neither size nor time constraints are likely to have been limiting at the time of moulting in our Type II larvae.

One possible explanation of lower instar: instar weight ratios in larvae with more instars is that larvae may be able to add instars by lowering their critical weight for moulting, perhaps as a "strategy". Smaller weights at moulting then mean that more instars are needed to reach the pupation threshold. However, this hypothesis requires an unknown mechanism, rather than oxygen levels, by which larvae could set and detect a reduced critical weight. A more parsimonious explanation of how extra instars may originate is that of Jones et al. (1981). Even with the same critical weight, a lower RGR may result in a smaller larva after the moult due to less growth in the interval between reaching the critical weight and when growth stops upon moulting. This period consists of (a) the time until the "gate" - a window of time in the scotophase during which the brain can release prothoracicotropic hormone (PTTH) which begins the endocrine cascade leading to moulting (Jones et al., 1981; Safranek \& Williams, 1984); and then (b) the period until cessation of feeding, which is about 18 $\mathrm{h}$ in M. sexta and does not appear to vary with RGR (Safranek \& Williams, 1984; see also Davidowitz et al., 2004). Period (a) will be shorter for a larva that doesn't reach its critical weight until during the gate or only a short way in advance of it. This larva will then gain less weight before the moult, be smaller after the moult, and exhibit a smaller instar: instar weight ratio for that moult. A small size after a moult will cause the next moult to result in a small larva also, because the critical weight depends on, and is a ratio of, the weight at the beginning of the moult. The effect will accumulate up the instars, meaning the pupation threshold is not reached in the fifth instar and another instar ensues (Jones et al., 1981). A moult into a small larva early in development therefore, or even a lesser provisioned egg, could mean that, from that point on, undergoing an extra instar is inevitable to meet the pupation size threshold. Type II P. suavis had smaller second instars on average, and others have noted that higher instar numbers tend to result from smaller larvae (Kamata \& Igarashi, 1995; Esperk \& Tammaru, 2006; Esperk \& Tammaru, 2010) with lower early growth rates (Kingsolver, 2007) or from smaller eggs (Leonard, 1970; Barata et al., 2001). Possible effects of egg quality could explain why parental density is sometimes seen to have an effect on the instar number of offspring (Morita \& Tojo, 1985).

This elegant hypothesis, here referred to as the "standard critical weight ratio hypothesis", can explain why a slower growing larva may not be able to simply grow for longer to achieve the same weights at moulting as other larvae, and pupate in the same number of instars. The time periods (a) and (b) have the effect of rendering the size of the larva after the moult proportional not so much to the critical weight, but to the size the larva has reached at a cut-off point in time. Period (a) may be shorter because of a lower RGR, or perhaps even because of hatching as a neonate later in the day. The gate in M. sexta is 10-14 h long (Truman, 1972) and so period (a) could range from $0 \mathrm{~h}$ (when reaching critical weight during the gate) to $14 \mathrm{~h}$ (reaching critical weight just after the previous gate). Even with the same RGR, in the case of two $P$. suavis larvae growing at $20 \%$ of their body weight per day, such a difference in a period (a) could mean one larva gains $12 \%$ in body weight before moulting that the other does not. Low RGR may then also cause low weight gain during periods (a) and (b). In the "standard critical weight ratio" scenario, the gate is a source of variation in size after the moult even with little variation in RGR under standard rearing conditions.

It is important to note that under this "standard critical weight ratio" scenario, larvae are compensating not for low growth rates per se, but for a small size after a moult. This would explain why not all low RGR larvae have six instars. Type II P. suavis larvae had significantly lower early weights and low RGR, but only on average; there was some overlap in RGR and weights between the two Types, rather than there being a threshold growth rate below which larvae became Type II. This could be due to natural variation around a standard critical weight ratio, but would occur anyway under Jones et al.'s (1981) hypothesis. Larvae will be a range of sizes after the moult depending on the distance to the gate they hit and growth during times (a) and (b). A low RGR larva, for example, could end up bigger after the moult than a higher RGR larva, depending on the difference in RGRs. A low RGR larva could miss the gate altogether and achieve the critical weight some way before the subsequent gate, while a higher RGR larva could hit its critical weight during a previous gate. In this way a larva with higher than average RGR may also sometimes need an extra instar to reach pupation. An overall reduction in RGR in the population, such as in adverse conditions, might result in more larvae hitting their critical weight closer to or during the gate, and/or having reduced growth in periods (a) and (b). Others have observed increases in percentages of Type II under starvation or low temperatures (e.g. Morita \& Tojo, 1985; see also Introduction).

It is not known if $P$. suavis has a gate, but these are known from M. sexta, Trichoplusia ni (Hübner) (Jones et al., 1981), and Pseudoplusia includens (Walker) (Strand, 1990), and presumed to be widespread. If the gate did not exist in a particular species, lower growth in period (b) could still result in larvae too small after the moult to pupate in five instars, though in the gateless case it would always be the lower RGR larvae that are smaller after the moult and require more instars. Clearly, where the gate exists, it prevents a larva fully optimising the timing of its moults. Reaching a critical weight well in advance of a gate may mean being metabolically limited towards the end of an instar. Reaching a critical weight just before or during 
the gate, however, may mean moulting at a small size and bearing the time and resource costs of an additional instar, while gaining a larger pupal size. Part of the lower AGR of Type II larvae is likely to be due to these costs. The gate however may perform the important function of timing the moult in relation to the photophase, to reduce predation and dehydration, in which case it is likely to be strongly selected for.

Type II P. suavis larvae had shorter third instars (by 0.6 days) and fourth instars (by 1.1 days) than Type I larvae, and on average had lower RGR. One question with the "standard critical ratio hypothesis" is whether the same critical weight ratio can account for shorter instars in larvae with lower mean RGR. A larva that is smaller after a moult due to low RGR will have a lower critical weight to reach next time, but at a low RGR will not reach it sooner than a higher RGR larva reaches its higher critical weight, except possibly under certain gate circumstances. Mostly, larvae reaching critical weight before the same gate will moult at a similar time, though perhaps later if they reach the critical weight partway through the gate's duration, which could shorten the following instar. Larvae that miss the gate and hit their critical weight before the next gate add as much as a day to their instar duration. Another possibility for explaining shorter instars in Type II larvae is that in the case of two larvae currently having the same RGR, the larva that reached critical weight closer to the previous gate (perhaps due to eggs hatching later, or a hiatus in growth), will inevitably have a shorter subsequent instar. The larva will have had a smaller weight after the moult and thus has a lower critical weight to reach next time, and with the same RGR will reach it sooner. Other researchers have found their "Type II" larvae to have some instars shorter by 0.6 to $1 \mathrm{~d}$ than the comparable instars in "Type I" larvae (Morita \& Tojo, 1985; Kamata \& Igarashi, 1995). Shorter instars in larvae with higher number of instars have been noted in other lepidopteran species, such as Orgyia antiqua (L.) and Lymantria dispar (L.) (Esperk \& Tammaru, 2006), and Spodoptera litura from our own laboratory colony (unpubl. data).

Under the "standard critical weight ratio" hypothesis, then, variable instar in lepidopteran species is a normal and inevitable consequence of physiological constraints around larval-larval moults where gates and pupation thresholds exist, rather than being an optional "strategy". Variation in the RGR of larvae, combined with timing constraints after the critical weight for moulting is reached, results in greater variation in size after early moults such that some larvae will not reach the pupation threshold in the lower number of instars. If this is correct, the existence of a pupation threshold is the main "cause" of the ability to add instars. Larvae that are smaller in early instars are able to take longer to become normal adults. Individuals of timestressed species in highly seasonal environments where foliage quality rapidly deteriorates, that have lower growth rates than others in the population, may favour pupating at the same time as others but at lower weights (Nylin \& Gotthard, 1998; Tammaru et al., 2004). Pseudocoremia suavis is not a time-stressed species, feeding on evergreens in a warm-temperate environment. Larvae disperse on silk threads in the first instar and could suffer early periods of starvation and low growth rate, necessitating a pupation threshold and the ability to add instars. Leonard (1970) notes that in Lymantria dispar, which disperses in the first instar, a prolonged first instar is often followed by extra instars. The larger eventual body size of Type II $P$. suavis is also a consequence of the same physiological constraints. A short way through the sixth instar, Type II larvae were likely to have been over the weight at which pupation is triggered in the fifth instar of Type I larvae (Fig. 1), and they appear to simply continue their sixth instar until reaching the critical weight for that instar. It is possible that the slower, larger developmental pathway is advantageous or disadvantageous at different times of year or environmental conditions. If P. suavis are able to "choose" their Type, it is possible that the mechanism would be the degree of egg provisioning, or in larvae, the ability to alter feeding and therefore the timing of reaching critical weight.

Given these reasons proposed for variable instar number, this phenomenon may be more widespread in Lepidoptera than is currently recorded, especially in non time-stressed species. It seems possible that variation in instar number, unless moults are followed, may be overlooked in many species, especially in observations from field studies. However, the study of laboratory colonies may mislead in some cases, for example long-established laboratory populations of $M$. sexta have high growth rates and are highly synchronized, and are known to always have five instars under standard rearing conditions, whereas larvae from field populations studied by Kingsolver (2007) may have five or six instars.

Around $21 \%$ of parasitoids emerged from the fourth host larval instar $\left(4^{\text {th }} \mathrm{IE}\right)$, while most emerged from the fifth instar $\left(5^{\text {th }} \mathrm{IE}\right)$. This bimodal distribution of emergence could be the result of shorter development time for parasitoids oviposited into a bigger resource; $4^{\text {th }}$ IE hosts were bigger on average on parasitisation day than $5^{\text {th }}$ IE hosts. It is commonly known that larger hosts produce parasitoids sooner and/or larger (Godfray, 1994). Although emerging later, $5^{\text {th }}$ IE parasitoids had bigger cocoons than $4^{\text {th }}$ IE parasitoids (but the same number of eggs) and had the same AGR, and may or may not have been disadvantaged. Another possible explanation for the bimodal distribution is that Types are present in parasitised larvae, and $4^{\text {th }}$ IE parasitoids were growing in hosts that if unparasitised would have had five instars, and $5^{\text {th }}$ IE parasitoids in hosts that would have had six instars. Supportive of this is that parasitoids emerged from hosts of approximately $25-35 \mathrm{mg}$ and this weight range falls within the $4^{\text {th }}$ instar in unparasitised Type I larvae and within the $5^{\text {th }}$ instar in unparasitised Type II larvae (Fig. 2). Also strongly supportive is the correspondence in estimated moulting weights between Type I and $4^{\text {th }}$ IE hosts, and Type II and $5^{\text {th }}$ IE hosts (Table 4). The pattern of instar durations is also similar - while parasitised hosts all together had lower growth rates and longer instars than unparasitised hosts (Fig. 3), within the parasitised larvae 
$5^{\text {th }}$ IE hosts had lower growth rates but a shorter third instar than $4^{\text {th }}$ IE hosts, and their estimated moulting weights were much lower (Fig. 4), similar to Type II larvae when compared with Type I. Alternatively, it could be proposed that $M$. pulchricornis in slower growing hosts is able to adjust the length of host instars to "add" an extra instar to optimise timing of emergence and cocoon weight. It is difficult to determine whether increased host instar duration is due to passive regulation by a parasitoid (i.e. when parasitoid feeding lowers host growth rate) or active regulation via hormones (Godfray, 1994). However, the simpler explanation of lengthened host instars due to lowered growth rates via parasitoid feeding, with moulting at normal critical weights with the gate and timing limitations producing the two Types, fits all of the data and would result in exactly the instar duration differences that are seen when comparing within and between unparasitised and parasitised larvae. Meteorus pulchricornis does not seem to be regulating the host instars except in the emergence instar, where moulting after the usual instar duration is prevented either hormonally or via weight reduction as the host ceases eating while the parasitoid prepares to emerge. In parasitised larvae then, we see that indeed larvae of low RGR can stay in their instar longer to moult at a normal weight, and the same gate/timing constraints seem to be operating to produce the same two Types.

Liu \& Li $(2006,2008)$ found that Spodoptera exigua (Hübner) and Helicoverpa armigera similarly have two possible instars of emergence when parasitised in the same instar by M. pulchricornis, over various instars of oviposition. This could have been due to variation in initial size of the host and variation in parasitoid growth rates. However, these hosts can be variable in instar (Casimero et al., 2000; Azidah \& Sofian-Azirun, 2006) and even though hosts are destined not to pupate, it seems possible that parasitoid final size and development time, and studies analysing these, could be affected by variable instar in many host-parasitoid systems. All but one of our M. pulchricornis emerged at least 6 days after a host moult. They may be constrained by host hormones in when they can emerge, and so parasitoids emerging in a later instar may inevitably end up bigger.

The proportion of parasitised hosts that are $5^{\text {th }} \mathrm{IE}$ is higher than the proportion of unparasitised hosts that are Type II, in all three replicates $(75.0 \% \pm 8.8$ compared to $46.3 \pm$ 8.1). This increase in percentage of presumed "Type II" larvae under the reduced RGR of parasitism provides support for the proposition that lower RGR tends to result in lower instar: instar weight ratios. Host larvae were parasitised in the second instar. It is likely that some larvae, after the first moult or from the egg, were already set on the Type II growth schedule, and that the reduction in RGR after parasitisation caused reduction in the weight after the next moult for more larvae to switch them to the "Type II" category. However, in our parasitised P. suavis larvae, even though they had much lower RGR than unparasitised larvae, we did not we see evidence of a seven instar Type, i.e. hosts with very short instar durations producing parasitoids in a sixth instar. Neither were further Types such as fourth or seventh instar-pupating larvae observed in unparasitised larvae. This supports the idea that it is not lower RGR in itself that necessitates extra instars, but that they are a compensation for small size after the moult. The amount of weight a larva can gain after reaching its critical weight will fall within limits, these largely depending on the maximum and minimum distance to the gate. These limits will apply whichever gate a larva hits, meaning that even very slow-growing larvae can reach pupation in six instars. However, an unusually small egg might produce a neonate too small to pupate in six instars. Also, in limited nutrition conditions, presumably small stationary moults that occur below the critical weight threshold would necessitate more than six instars.

While M. pulchricornis appears not to regulate the nonemergence instars of $P$. suavis, this parasitoid is known to be capable of inducing contrasting responses in hosts of different sizes. Meteorus pulchricornis has a very wide host range and is able to reduce the size of a large host Mythimna separata (Walker) by $95 \%$, and to increase the size of a small host Plutella xylostella (L.) by $30 \%$, in order to optimize host conditions for development (Harvey et al., 2010). How instar number, instar duration and moulting weights are affected in these hosts is unknown and would benefit from further research. Parasitism can be a useful tool to examine physiological limitations and capabilities of their hosts, and perhaps help distinguish between life history strategies and physiological limitations.

ACKNOWLEDGEMENTS. We thank G. Walker and F. MacDonald for supplying Meteorus pulchricornis, H. Barraclough for mathematical advice, and C. Walter and A. Wagner of Scion Research for providing Pinus radiata.

\section{REFERENCES}

Alma P.J. 1975: A Study of Captures of Noctuidae and Geometridae in a Light-trap at the Forest Research Institute, Rotorua. Forest Entomology Report No. 43, New Zealand Forest Service, Forest Research Institute, Rotorua, $35 \mathrm{pp}$.

AzIDAh A.A. \& Sofian-AzIrun M. 2006: Life history of Spodoptera exigua (Lepidoptera: Noctuidae) on various host plants. - Bull. Entomol. Res. 96: 613-618.

Barata C., Baird D.J. \& Soares A.M.V.M. 2001: Phenotypic plasticity in Daphnia magna Straus: variable maturation instar as an adaptive response to predation pressure. - Oecologia 129: 220-227.

Barraclough E.I., Burgess E.P.J., Philip B.A., Wohlers M.W. \& MaLone L.A. 2009: Tritrophic impacts of Bt-expressing transgenic pine on the parasitoid Meteorus pulchricornis (Hymenoptera: Braconidae) via its host Pseudocoremia suavis (Lepidoptera: Geometridae). - Biol. Contr. 49: 192-199.

Berndt L., Brockerhoff E.G., Jactel H., Weis T. \& Beaton J. 2004: Biology and rearing of Pseudocoremia suavis, an endemic looper (Lepidoptera: Geometridae) with a history of outbreaks on exotic conifers. - N. Z. Entomol. 27: 73-82.

BERRY J.A. 1997: Meteorus pulchricornis (Wesmael) (Hymenoptera: Braconidae: Euphorinae), a new record for New Zealand. - N. Z. Entomol. 20: 45-48.

Blackman V.H. 1919: The compound interest law and plant growth. - Ann. Bot. 33: 353-360.

Burgess E.P.J., Barraclough E.I., Kean A.M., Walter C. \& Malone L.A. 2011: No impact of transgenic nptII-leafy Pinus 
radiata (Pinales: Pinaceae) on Pseudocoremia suavis (Lepidoptera: Geometridae) or its endoparasitoid Meteorus pulchricornis (Hymenoptera: Braconidae). — Environ. Entomol. 40: $1331-1340$

Burgess E.P.J., Kean A.M., Barraclough E.I., Poulton J., WaDASinghe G., Markwick N.P. \& Malone L.A. 2014: Evaluation of the field impacts of simulated Bacillus thuringiensis-transgenic Pinus radiata on nontarget native Lepidoptera and their natural enemies in a New Zealand plantation forest. - Agric. Forest Entomol. 16: 63-74.

Callier V. \& Nijhout H.F. 2011: Control of body size by oxygen supply reveals size-dependent and size-independent mechanisms of molting and metamorphosis. - Proc. Nat. Acad. Sci. USA 108: 14664-14669.

Casimero V., Tsukuda R., Nakasuji F. \& Fujisaki K. 2000: Effect of larval diets on the survival and development of larvae in the cotton bollworm, Helicoverpa armigera Hübner (Lepidoptera: Noctuidae). - Appl. Entomol. Zool. 35: 69-74.

Davidowitz G., D’Amico L.J. \& NiJhout H.F. 2004: The effects of environmental variation on a mechanism that controls insect body size. - Evol. Ecol. Res. 6: 49-62.

Dugdale J.S. 1958: Structural characters of the larva of Selidosema suavis (Butler) (Lepidoptera: Geometridae, Subfamily Ennominae). - N. Z. Entomol. 2: 24-33.

Esperk T. \& TAmmaru T. 2004: Does the 'investment principle' model explain moulting strategies in lepidopteran larvae? Physiol. Entomol. 29: 56-66.

EsPerk T. \& TAmmaru T. 2006: Determination of female-biased sexual size dimorphism in moths with a variable instar number: The role of additional instars. - Eur. J. Entomol. 103 $575-586$.

ESPERK T. \& TAMmARU T. 2010: Size compensation in moth larvae: attention to larval instars. - Physiol. Entomol. 35: 222-230.

ESPERK T., TAMMARU T. \& NYLIN S. 2007a: Intraspecific variability in number of larval instars in insects. - J. Econ. Entomol. 100: $627-645$.

Esperk T., Tammaru T., Nylin S. \& Teder T. 2007b: Achieving high sexual size dimorphism in insects: females add instars. Ecol. Entomol. 32: 243-256.

Etile E. \& Despland E. 2008: Developmental variation in the forest tent caterpillar: life history consequences of a threshold size for pupation. - Oikos 117: 135-143.

Fuester R.W., Taylor P.B., Peng H. \& Swan K. 1993: Laboratory biology of a uniparental strain of Meteorus pulchricornis (Hymenoptera: Braconidae), an exotic larval parasite of the gypsy moth (Lepidoptera: Lymantriidae). — Ann. Entomol. Soc. Am. 86: 298-304.

GenStat 2007: GenStat for Windows 10th Edition. VSN International, Hemel Hempstead, UK (www.vsni.co.uk/software/ genstat).

Godfray H.C.J. 1994: Parasitoids: Behavioral and Evolutionary Ecology. Princeton University Press, Princeton, xi $+473 \mathrm{pp}$.

Gould J., Venette R. \& Winograd D. 2005: Effect of temperature on development and population parameters of Copitarsia decolora (Lepidoptera: Noctuidae). — Environ. Entomol. 34: $548-556$.

GreENLEe K.J. \& HarRISON J.F. 2005: Respiratory changes throughout ontogeny in the tobacco hornworm caterpillar, Manduca sexta. - J. Exp. Biol. 208: 1385-1392.

Harvey J.A., SANo T. \& TANAKA T. 2010: Differential host growth regulation by the solitary endoparasitoid, Meteorus pulchricornis in two hosts of greatly differing mass. - J. Insect Physiol. 56: 1178-1183.

Honek A. 1993: Intraspecific variation in body size and fecundity in insects - a general relationship. - Oikos 66: 483-492.
Jensen J.G. \& CAmeron C.A. 2004: Development and kikuyu consumption of preimaginal Herpetogramma licarsisalis (Lepidoptera: Pyralidae) reared at temperatures between 15 and $25^{\circ} \mathrm{C}$. - Environ. Entomol. 33: 1178-1184.

Jones D., Jones G. \& Hammock B.D. 1981: Growth parameters associated with endocrine events in larval Trichoplusia $n i$ (Hübner) and timing of these events with developmental markers. - J. Insect Physiol. 27: 779-788.

KAMATA N. \& IgARASHI M. 1995: Relationship between temperature, number of instars, larval growth, body size, and adult fecundity of Quadricalcarifera punctatella (Lepidoptera: Notodontidae): Cost-benefit relationship. - Environ. Entomol. 24: 648-656.

KaY M. 1983: Resistance of Douglas fir to Pseudocoremia suavis. - N. Z. J. Forestry Sci. 13: 46-52.

KingSOLVER J.G. 2007: Variation in growth and instar number in field and laboratory Manduca sexta. — Proc. R. Soc. Lond. (B) 274: 977-981.

LEONARD D.E. 1970: Intrinsic factors causing qualitative changes in populations of Porthetria dispar (Lepidoptera: Lymantriidae). - Can. Entomol. 102: 239-249.

LiU Y.H. \& Li B.P. 2006: Developmental interactions between Spodoptera exigua (Noctuidae: Lepidoptera) and its uniparental endoparasitoid, Meteorus pulchricornis (Braconidae: Hymenoptera). - Biol. Contr. 38: 264-269.

LiU Y.H. \& Li B.P. 2008: Effects of Helicoverpa armigera (Noctuidae, Lepidoptera) host stages on some developmental parameters of the uniparental endoparasitoid Meteorus pulchricornis (Braconidae, Hymenoptera). - Bull. Entomol. Res. 98: 109-114.

Minitab 2010: Minitab 16 Statistical Software. Minitab Inc, State College, PA (www.minitab.com).

Morita M. \& Tojo S. 1985: Relationship between starvation and supernumerary ecdysis and recognition of the penultimate larval instar in the common cutworm, Spodoptera litura. $-J$. Insect Physiol. 31: 307-313.

NisHout H.F. 1975: A threshold size for metamorphosis in tobacco hornworm, Manduca sexta (L.). - Biol. Bull. 149: 214-225.

Nylin S. \& Gotthard K. 1998: Plasticity in life-history traits. Annu. Rev. Entomol. 43: 63-83.

SafraneK L. \& Williams C.M. 1984: Determinants of larval molt initiation in the tobacco hornworm, Manduca sexta. - Biol. Bull. 167: 568-578.

Sehnal F. 1985: Growth and life cycles. In Kerkut G.A. \& Gilbert L.I. (eds): Comprehensive Insect Physiology, Biochemistry and Pharmacology. Vol. 2. Pergamon Press, Oxford, pp. 1-86.

Singh P. \& Moore R.F. 1985: Handbook of Insect Rearing. Vols I and II. Elsevier Science, Amsterdam, viii $+488+$ viii +514 pp.

STRAND M.R. 1990: Characterization of larval development in Pseudoplusia includens (Lepidoptera: Noctuidae). - Ann. Entomol. Soc. Am. 83: 538-544.

Tammaru T., Nylin S., Ruohomaki K. \& Gotthard K. 2004: Compensatory responses in lepidopteran larvae: a test of growth rate maximisation. - Oikos 107: 352-362.

TRuman J.W. 1972: Physiology of insect rhythms: I. Circadian organization of the endocrine events underlying the moulting cycle of larval tobaco hornworms. - J. Exp. Biol. 57: 805-820.

Zondag R. 1956: Selidosema suavis. Control Plan No. 5. In: Forest Insect Survey Newsletter 5. Forest Research Institute, New Zealand Forest Service, Rotorua, pp. 21-34.

Received November 5, 2013; revised and accepted June 10, 2014 Prepublished online August 15, 2014 